Reply

\title{
A Reply to Keith Schofield: Comment on Ernest et al. Programmable Thermal Dissociation of Reactive Gaseous Mercury, a Potential Approach to Chemical Speciation: Results from a Field Study. Atmosphere $2014,5,575-596$
}

\author{
Anthony J. Hynes ${ }^{1, *}$, Cheryl Tatum Ernest ${ }^{1,+}$, Deanna Donohoue ${ }^{1, \ddagger}$, Dieter Bauer 1 \\ and Arnout Ter Schure ${ }^{2}$ \\ 1 Division of Marine and Atmospheric Chemistry, Rosenstiel School of Marine and Atmospheric Science, \\ University of Miami, 4600 Rickenbacker Causeway, Miami, FL 33149, USA; cheryl.ernest@mpic.de (C.T.E.); \\ deanna.l.donohoue@lawrence.edu (D.D.); dbauer@rsmas.miami.edu (D.B.) \\ 2 Electric Power Research Institute, 3420 Hillview Avenue, Palo Alto, CA 94304, USA; aterschu@epri.com \\ * Correspondence: ahynes@rsmas.miami.edu; Tel.: +1-305-421-4173; Fax: +1-305-421-4689 \\ † Current address: Atmospheric Chemistry Department, Max Planck Institute for Chemistry, \\ Hahn-Meitner-Weg 1, D-55128 Mainz, Germany. \\ $\ddagger$ Current address: Department of Chemistry, Lawrence University, Appleton, WI 54911, USA. \\ Academic Editor: Robert W. Talbot \\ Received: 23 August 2016; Accepted: 31 August 2016; Published: 19 September 2016
}

Dr. Schofield [1] states that:

\begin{abstract}
"The authors of this paper utilized a so-called "Programmable thermal dissociation method" to monitor $\mathrm{HgCl}_{2}$ emitted from a coal fired Florida combustion plant. By comparison, they did confirm that the emitted mercury compound was in fact the dichloride, which is in fact the only such plausible molecule for mercury. However, the subtle implications in the paper that the $\mathrm{HgCl}_{2}(\mathrm{~g})$ molecule is not thermally stable and can readily dissociate in the gas phase at temperatures below $300{ }^{\circ} \mathrm{C}$ is not consistent with a very broad spectrum of chemical information and clearly can be misleading and incorrect if not more fully explained."
\end{abstract}

The work described in our manuscript [2] relates to observations of the programmable thermal dissociation (PTD) of reactive gaseous mercury (RGM) collected on denuders and comparison of these PTD profiles with "calibration" profiles obtained using pure $\mathrm{HgCl}_{2}$. We believe that this is a surface-mediated process and, in our view, it is not germane to the gas phase stability of $\mathrm{HgCl}_{2}$. Our paper makes no claims or assertions, subtle or otherwise, about the stability of gas-phase $\mathrm{HgCl}_{2}$. Our detection technique, laser-induced fluorescence (LIF), only detects gas-phase elemental mercury (GEM, $\mathrm{Hg}(0))$ and these experiments provide an unambiguous identification of the surface-mediated thermal dissociation of $\mathrm{HgCl}_{2}$ as a function of temperature. As we note below, our experiments do not exclude a sublimation channel. Because LIF does not detect $\mathrm{HgCl}_{2}$ in the gas phase, we do not know if sublimation is significant.

To be clear, we reproduce part of Section 3.2 from the manuscript [2] that describes Programmable Thermal Dissociation:

"In contrast to the studies of mercury containing solids, the configuration of PTD utilized in this work is designed to sample gas phase RGM. During the thermal analysis we use laser-induced fluorescence to monitor the extent of RGM decomposition as a function of temperature in real time by measuring the evolution of GEM produced during decomposition. The RGM sample is obtained by pulling the analysis gas through a quartz or Pyrex tube that acts as a denuder and captures RGM 
but transmits elemental and particulate mercury. It should be emphasized that these are uncoated tubular denuders in contrast to the $\mathrm{KCl}$ coated annular denuders that are commonly used to quantify total RGM. The collection efficiency of the denuder is not known and, in this configuration, PTD is not designed to produce a quantitative measurement of RGM concentration. After a period of sampling the denuder is transported to a laboratory, flushed with He and then heated in a series of temperature ramps in an oven. As the denuder temperature increases, RGM dissociates and the GEM product is desorbed from the denuder wall. The GEM evolution is monitored in real time using laser-induced fluorescence (LIF). Comparison of the PTD profiles of unknown samples with profiles of known oxidized mercury compounds may provide information on the chemical identity of the sample. Since PTD is an indirect technique and different compounds can have identical or very similar decomposition properties it is unlikely to provide a definitive molecular identification. However, it should be possible to indicate whether the PTD profile of a sample is consistent with a particular molecular species or class of species."

Again, we note that the LIF technique is very specific and only detects gas-phase elemental mercury (GEM, $\mathrm{Hg}(0))$. If the $\mathrm{HgCl}_{2}$ sublimes, it will not be detected.

Dr. Schofield is correct in pointing out that Nagayama and Takakda [3] found no evidence for dissociation in a study that combined thermogravimetric analysis with atomic absorption spectroscopy. We thank Dr. Schofield for bringing this reference to our attention. We would note that in this work the authors used pure, i.e., undiluted, $\mathrm{HgCl}_{2}$ and stated that a minimum sample size of $0.5 \mathrm{mg}$ was required, with $5 \mathrm{mg}$ being required for a good thermogram.

In contrast to this study, we note the following work that we did cite:

Bister and Scholz [4], used PTD to examine mercury speciation in contaminated soils. They used atomic absorption for the detection of GEM. Calibration samples were diluted with quartz powder. To distinguish between desorption and decomposition, the vapor passed through an $800{ }^{\circ} \mathrm{C}$ quartz pyrolysis tube before analysis, thus measuring the sum of desorption and decomposition. By bypassing the pyrolyzer, they could monitor decomposition alone. Their PTD profile of $\mathrm{HgCl}_{2}$ shows decomposition starting at $\sim 80^{\circ} \mathrm{C}$ and peaking at $200^{\circ} \mathrm{C}$. They saw no difference in PTD profiles obtained by bypassing the pyrolyzer and they concluded that decomposition was occurring exclusively. The samples used were heavily diluted and they give a detection limit of $40 \mathrm{ng}$ of $\mathrm{Hg}(0)$.

Wu et al. [5], cited by both our paper and Schofield, examined the decomposition/desorption of $\mathrm{HgCl}_{2}$ diluted by a factor of 3000 in, among other compounds, quartz powder. Figure 9 of this paper shows a thermal dissociation/desorption profile of $\mathrm{HgCl}_{2}$ diluted in quartz powder that shows components from both decomposition and sublimation. In this work, the shape of the thermal profile and the relative amounts of dissociation differed greatly depending on the diluent. For most of the diluents, i.e., quartz powder, $\mathrm{HgCl}_{2}$ would be adsorbed rather than absorbed, clearly indicating that this is a surface-mediated process.

We should point out that while our work is consistent with the reports of both Bister and Scholz [4] and $\mathrm{Wu}$ et al. [5], it is a very different experiment. In our work very small amounts, ng levels, are deposited from the gas phase onto the denuder surface rather than taking diluted solid samples. In addition, we are "blind" to any sublimation channel because we only detect gas-phase $\mathrm{Hg}(0)$.

We would again note the conclusions of our paper: "The PTD profiles of the stack and plume samples are consistent with $\mathrm{HgCl}_{2}$ being the chemical form of the sampled RGM. Comparison with literature PTD profiles of reference mercury compounds suggests no other likely candidates for the speciation of RGM." To the best of our knowledge this is the only measurement reported in the literature that provides an identification, albeit indirect, of the speciation of RGM in the stack gas of a coal-fired power plant. We would like to again stress that we do not believe our PTD observations are relevant to the gas-phase stability of $\mathrm{HgCl}_{2}$ and that the manuscript contains no implication, subtle or otherwise, that this is the case. Indeed, we specifically state in the manuscript (Section 3.3.1 Sampling during the Crist Campaign): "Mercury emissions were dominated by the exhaust from unit \#7, which typically contained 5-7 $\mu \mathrm{g} \cdot \mathrm{m}^{-3}$ of mercury, more than $90 \%$ of which was present as RGM." 
To the best of our knowledge, $\mathrm{HgCl}_{2}$ was never directly identified in any of the work on "induced conversion of $\mathrm{Hg}(\mathrm{g})$ to $\mathrm{HgCl}_{2}(\mathrm{~g})$ " discussed by Dr. Schofield, but rather its presence was inferred because it is "the only such plausible molecule for mercury".

Conflicts of Interest: The authors declare no conflict of interest.

\section{References}

1. Schofield, K. Comment on Ernest et al. Programmable Thermal Dissociation of Reactive Gaseous Mercury, a Potential Approach to Chemical Speciation: Results from a Field Study. Atmosphere 2014, 5, 575-596. Atmosphere 2016, 7, 119.

2. Ernest, C.T.; Donohoue, D.; Bauer, D.; Schure, A.T.; Hynes, A.J. Programmable Thermal Dissociation of Reactive Gaseous Mercury, a Potential Approach to Chemical Speciation: Results from a Field Study. Atmosphere 2014, 5, 575-596. [CrossRef]

3. Nagayama, K.; Takada, T. Direct combination of thermogravimetric analyzer and atomic absorption spectrometer for detection of atomic vapor in thermal analysis. Thermochim. Acta 1989, 156, 11-19. [CrossRef]

4. Bister, H.; Scholz, C. Determination of Mercury Binding Forms in Contaminated Soils: Mercury Pyrolysis versus Sequential Extractions. Environ. Sci. Technol. 1997, 31, 233-239. [CrossRef]

5. Wu, S.; Uddin, M.A.; Nagano, S.; Ozaki, M.; Sasaoka, E. Fundamental Study on Decomposition Characteristics of Mercury Compounds over Solid Powder by Temperature-Programmed Decomposition Desorption Mass Spectrometry. Energy Fuels 2011, 25, 144-153. [CrossRef]

(C) 2016 by the authors; licensee MDPI, Basel, Switzerland. This article is an open access article distributed under the terms and conditions of the Creative Commons Attribution (CC-BY) license (http://creativecommons.org/licenses/by/4.0/). 